\title{
KEPUASAN KONSUMEN GENARSI Z PADA PEMBELIAN ONLINE
}

\author{
Novika Rahmatika', Deni Ramdani² \\ Universitas Tidar
}

rahmatikanovika@gmail.com1; deni.ramdani@untidar.ac.id ${ }^{2}$

\begin{abstract}
ABSTRAK
Generasi Z dan Milenial menjadi penduduk yang mendominasi Indonesia didominasi oleh usia produktif. 90 persen barang yang dijual online adalah produk impor dari negara asing, terdapat tiga platfrom marketplace yang paling sering digunakan oleh pembeli online warga Indonesia yaitu Alibaba dan Aliexpress asal Cina, serta Amazon asal Amerika Serikat. Teknik pengumpulan data yang bersifat sekunder dan primer, data yang digunakan dalam penelitian ini yaitu melalui kuisoner atau angket dan studi pustaka. Jensi data yang diambil adalah data yang berjenis crossection. Dalam penelitian ini teknik analisis data yang digunakan yaitu Uji Validitas, Uji Realibilitas untuk menguji kusioner yang diberikan dari indikator yang telah ditetapkan. Hasil penelitian disini menyatakan bahwa variabel kualitas produk tidak berpengaruh terhadap kepuasan pelanggan, sehingga Hipotesis 1 ditolak. Sedangkan harga berpengaruh terhadap variabel kepuasan pelanggan sehingga hipotesis 2 diterima. Kualitas produk dan harga secara simultan berpengaruh terhadap kepuasan pelanggan.
\end{abstract}

Kata Kunci : Kualitas Produk, Harga dan Kepuasaan Pelanggan

\section{ABSTRACT}

Generation $Z$ and Millennials are the population that dominates Indonesia, dominated by productive age. 90 percent of goods sold online are imported products from foreign countries, there are three marketplace platforms that are most often used by Indonesian online buyers, namely Alibaba and Aliexpress from China, and Amazon from the United States. Data collection techniques are secondary and primary, the data used in this research is through a questionnaire and literature study. The type of data taken is crosssectional data. In this study, the data analysis technique used is Validity Test, Reality Test to test the questionnaire given from the indicators that have been set. The results of the research here state that the product quality variable has no effect on customer satisfaction, Hypothesis 1 is rejected. While the price has an effect on the customer satisfaction variable so that hypothesis 2 is accepted. Product quality and price simultaneously affect customer satisfaction.

Keywords: Product Quality, Price and Customer Satisfaction

Diterima: 10 September 2021; Direvisi: 28 September 2021; Diterbitkan: Oktober 2021

\section{PENDAHULUAN}

Internet saat ini sangat melekat dengan kehidupan masyarakat. Internet sangat membantu dalam kehidupan sehari-hari diantaranya yaitu aktivitas jual beli secara online yang memudahkan pembeli tanpa harus bertatap muka. Selain itu pembeli juga dapat memperoleh informasi secara luas. Salah satu platform 
yang banyak digunakan untuk aktivitas jual beli secara online yaitu marketplace. Situs marketplace menyediakan tempat untuk berjualan dan fasilitas pembayaran. Badan Pusat Statistik (BPS) merilis jumlah penduduk Indonesia hingga September 2020 tercatat sebanyak 270,20 juta jiwa (Badan Pusat Statistik, 2019). Generasi Z dan Milenial menjadi penduduk yang mendominasi, Generasi $\mathrm{Z}$ adalah mereka yang lahir pada 1997-2012 dan Generasi Milenial lahir pada tahun 1981-1996. Dengan demikian, Indonesia didominasi oleh usia produktif. 49\% transaksi ecommers disumbang oleh generasi millenial atau kosumen usia 26-35 tahun. Berdasarkan berita dari Tempo (2019) mengatakan bahwa data Kementerian Perindustrian, 90 persen barang yang dijual online adalah produk impor dari negara asing, terdapat tiga platfrom marketplace yang paling sering digunakan oleh pembeli online warga Indonesia yaitu Alibaba dan Aliexpress asal Cina, serta Amazon asal Amerika Serikat.

Sektor perdagangan berperan dalam mendukung kelancaran arus barang dan jasa, memenuhi kebutuhan pokok masyarakat, dan mendorong pembentukan harga yang wajar. Menjaga stabilitas ekonomi dalam mengendalikan inflasi dan memastikan neraca pembayaran. Belanja online saat ini menjadi sesuatu yang sedang gencar. Hal tersebut memicu persaingan antar pelaku binis. Persaingan yang sangat ketat membuat pelaku bisnis menciptakan berbagai strategi untuk bersaing dalam memenuhi kebutuhan dan keinginan konsumen agar konsumen merasa puas.

Pelanggan pada saati ini mendapatkan berbagai alternatif dalam memilih produk yang sesuai dengan minat dan kebutuhannya. Menurut Haryanto (2013) menuliskan bahwa pelanggan tidak sekedar membeli produk namun sekaligus membeli layanan yang menyertainya. Pada umumnya pelanggan akan merasa senang jika dilayani dengan sopan, ramah, dengan penuh perhatian dan dipandang penting sehingga akan timbul kepuasan dalam membeli barang / jasa dan menjadi loyal pada perusahaan tersebut. Kepuasan pelanggan terhadap perusahaan tidak terlepas dari kualitas produk yang ditawarkan dan kualitas pelayanan yang diberikan oleh produk tersebut. Menurut Lenzun et al. (2016) mengemukakan bahwa kualitas adalah kombinasi antara fitur dan karakteristik. Karakteristik tersebut menentukan sejauh mana kebutuhan pelanggan dapat dipenuhi, atau mengevaluasi seberapa besar fitur dan karakteristik tersebut memenuhi kebutuhan mereka.

Harga adalah salah satu komponen yang penting dalam memberikan konsumen kepuasaan, dengan harga yang terjangkau konsumen lebih puas dibandingkan dengan harga yang mahal pada suatu produk. Menurut Gofur (2019) menuliskan bahwa Semakin tinggi tingkat kualitas pelayanan menyebabkan semakin tingginya kepuasan pelanggan dan juga mendukung harga yang lebih tinggi serta biaya yang lebih rendah. Menurut Dwi (2012) mengatakan kepuasan ini dapat dicapai dengan memberikan kualitas layanan terbaik dan harga terjangkau bagi pelanggan. Loyalitas pelanggan dapat terbentuk ketika pelanggan merasa puas dengan tingkat pelayanan yang diterima dan pelanggan cenderung memilih produk atau jasa dengan keunggulan tetapi harga yang relatif murah.

Dalam memenuhi keinginan, kebutuhan serta harapan pelanggan agar terciptanya kepuasan pelanggan, maka para pelaku bisnis harus menciptakan strategi diantaranya adalah dengan 
memperhatikan kualitas produk. selain itu pelaku bisnis juga harus memperhatikan faktor harga. Penelitian ini bermaksud untuk mengetahui pengaruh kualitas produk, harga, terhadap kepuasan konsumen pembelian online pada generasi millenial di Kota Magelang.

\section{KAJIAN TEORETIK}

Kepuasan konsumen bisa di definisikan selaku penilaian pelanggan dari produk ataupun jasa sudah penuhi kebutuhan pelanggan serta ekspektasi konsumen. Kegagalan buat penuhi kebutuhan serta harapan konsumen diasumsikan selaku ketidakpuasan dengan layanan produk ataupun jasa. Pada dasarnya, kepuasan serta ketidakpuasan konsumen atas produk ataupun jasa hendak mempengaruhi pada pola sikap berikutnya. Menurut Sulistiyana (2015) menuliskan bahwa konsumen merasa puas, mereka hendak menampilkan besarnya mungkin kembali membeli produk ataupun jasa yang sama. Pelanggan yang puas pula cenderung hendak membagikan rujukan yang baik atas produk ataupun jasa yang sudah mereka pakai kepada orang lain. Menurut (Gofur, 2019) kepuasan Konsumen merupakan perasaan bahagia ataupun kecewa seorang yang timbul sehabis menyamakan kinerja (hasil) produk yang dipikirkan terhadap kinerja yang diharapkan. Bila kinerja produk lebih rendah dari pada harapan, konsumen hendak kecewa, bila nyatanya cocok harapan, konsumen hendak puas. bila melebihi harapan, pembeli hendak sangat puas.

\section{Kualitas Produk}

Kualitas produk adalah sebuah nilai yang diberikan oleh produsen kepada konsumen untuk dikonsumsi. Menurut
Amanah (2011) kualitas produk juga sangat mempengaruhi keberhasilan dan perkembangan usaha. Perusahaan yang menghasilkan produk berkualitas tinggi lebih menguntungkan daripada perusahaan yang menghasilkan produk inferior. Artinya konsumen akan rela membeli barang yang berkualitas dengan harga yang wajar / relatif terjangkau. Menurut Zebua (2020) kualitas berkaitan dengan karakteristik pengoperasian dasar produk.

Durabilitas artinya sudah berapa lama produk bisa digunakan sebelum harus diganti. Kepatuhan dengan spesifikasi mengacu pada sejauh mana produk memenuhi spesifikasi atau produk tidak memiliki cacat. Fungsi adalah fitur produk yang dirancang untuk meningkatkan fungsi produk atau meningkatkan minat konsumen terhadap produk tersebut. Reliabilitas adalah probabilitas suatu produk dapat memuaskan atau gagal berfungsi secara normal dalam kurun waktu tertentu. Estetika berkaitan dengan penampilan produk. Orang sering berpikir bahwa persepsi kualitas adalah hasil dari penggunaan pengukuran tidak langsung, karena konsumen mungkin tidak tahu atau kurang informasi tentang produk.

Kualitas adalah kemampuan suatu produk untuk menjalankan fungsinya, itu mencakup keseluruhan daya tahan produk, keandalan, presisi, kemudahan pengoperasian dan perbaikan, dan atribut berharga lainnya yang nantinya luarnya adalah mempengaruhi kepuasaan pelanggan Amstrong \& Kotler (2014). Hal ini searah dengan penelitian yang dilakukan oleh Gofur (2019), Amanah (2011) \& Lenzun et al. (2016). Sehingga hipotesis alternatif yang diajukan mengenai pengaruh kualitas produk terhadap kepuasan pelangaan sebagai berikut: 
H1: Kualitas produk diduga memiliki pengaruh positif signifikan terhadap kepuasan pelanggan.

\section{Harga}

Harga merupakan beberapa nilai yang ditukarkan buat suatu produk ataupun jasa. Lebih jauh lagi, harga merupakan beberapa nilai yang konsumen tukarkan buat jumlah khasiat dengan mempunyai ataupun memakai sesuatu benda ataupun jasa. Menurut Kotler (2012) Harga ialah perihal yang dicermati konsumen dikala melaksanakan pembelian. Sebagian konsumen apalagi mengidentifikasikan harga dengan nilai. Menurut Handoko (2017) mengatakan bahwa harga ialah beberapa uang (ditambah sebagian benda jika mungkin) yang diperlukan untuk memperoleh beberapa gabungan dari benda beserta pelayanannya.

Menurut Yulia (2015) strategi perusahaan untuk lebih menambah kepuasan pada pelanggan dengan memperhatikan faktor harga. Harga sebagai faktor petunjuk mutu produk yang nantinya berpengaruh pada kepuasaan pelanggan. Hal ini searah dengan penelitian yang dilakukan oleh Dwi (2012), Sulistiyana (2015) \& Lenzun et al. (2016). Kepuasan konsumen dipengaruhi oleh harga, kualitas pelayanan dan kualitas produk menurut Soehardi (2021). Sehingga hipotesis alternatif yang diajukan mengenai pengaruh kualitas produk terhadap kepuasan pelangaan sebagai berikut:

H2: Harga diduga memiliki pengaruh positif signifikan terhadap kepuasan pelanggan.

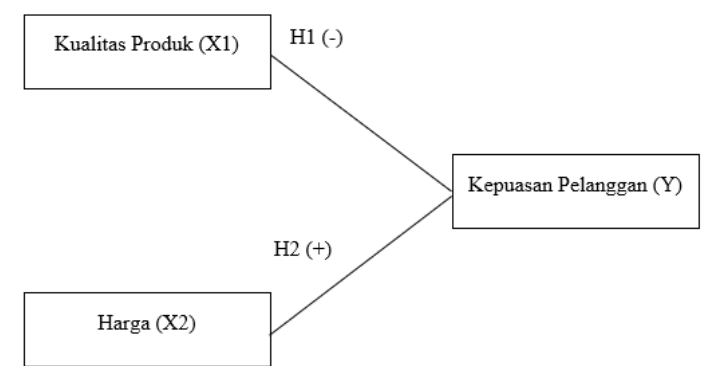

Gambar 1. Kerangka Pemikiran Teoritis Sumber: Gofur (2019), Dwi (2012), Sulistiyana (2015), Amanah (2011) \& Lenzun et al. (2016)

\section{METODE PENELITIAN}

Jenis yang dilakukan pada penelitian ini adalah kuantitatif deskriptif, digunakan untuk meneliti pada populasi atau sampel tertentu, pengumpulan data menggunakan instrument dan menjalaskan apa hasil dari penelitian ini menurut Sugiyono (2017).

Populasi pada penelitian ini adalah seluruh mahasiswa Universitas Tidar. Teknik pengambilan sampelnya adalah menggunakan teknik purposive sampling dimana terdapat kriteria yang ditentukan dalam penelitian ini, yaitu:

1. Mahasiswa Universitas Tidar angaktan tahun 2017 dan belum dinyatakan lulus. 2. Memilikki aplikasi marketplace.

3. Mempunyai pengalam melakukan transkasi diaplikasi marketplace tersebut.

Untuk menentukan ukuran sampel pada penelitian ini adalah menggunakan rumus Yamane dengan menggunakan sampling eror sebesar $5 \%$.

Teknik pengumpulan data yang bersifat sekunder dan primer, data yang digunakan dalam penelitian ini yaitu melalui kuisoner / angket dan studi pustaka dengan mengkaji berbagai buku dan jurnal yang relevan dengan penelitian ini guna memperoleh landasan teori yang terkait dengan penelitian ini serta 
pengumpulan dokumen-dokumen yang telah ada. Jensi data yang diambil adalah data yang berjenis crossection. Skala Pengukuran pada kusioner ini adalah dengan menggunakan skala likert, menggunakan skala likert karena ingin mengubah jawaban responden / data yang semula berbentuk narasi menjadi nilai yang numerik. Dalam penelitian ini, skala likert yang digunakan yaitu 5 poin.

Indikator dalam penelitian diterapkan pada kepuasan pembelian adalah kognitif, afektif dan konatif. Kualitas produk mempunyai beberapa indikator yaitu kinerja, daya tahan, kesesuaian, keandalan dan estetika. Harga mempunyai indikator keterjangkaun harga, daya saing harga dan kesesuaian harga.

Penelitian ini teknik analisis data yang digunakan yaitu Uji Validitas, Uji Realibilitas untuk menguji kusioner yang diberikan dari indikator yang telah ditetapkan. Untuk menguji hipotesis pada penelitian ini menggunakan uji-t, uji F \& analisis regresi linier berganda. Analisis regresi linier berganda adalah teknik statistik melalui koefisien parameter untuk mengetahui besarnya pengaruh variabel. Tujuannya yaitu dalam analisis regresi model yang baik merupakan model yang memenuhi asumsi klasik agar hasil dari penelitian dapat diinterpretasikan secara tepat dan akurat.

Metode regresi dalam penelitian ini adalah sebagai berikut:

$$
\begin{aligned}
& \mathrm{Y}=\alpha+\beta \_1 \mathrm{X} \_1+\beta \_2 \mathrm{X} \_2+\mathrm{e} \\
& \text { Keterangan: } \\
& \mathrm{Y}=\text { Kepuasan Pelanggan } \\
& \alpha=\text { konstanta } \\
& \beta=\text { koefisien regresi } \\
& \mathrm{X} 1=\text { Kualitas Produk } \\
& \mathrm{X} 2 \quad=\text { Harga } \\
& \mathrm{e}=\text { error term }
\end{aligned}
$$

\section{HASIL PENELITIAN DAN PEMBAHASAN}

Tabel 1. Uji Validitas

\begin{tabular}{lll}
\hline No & Indikator & R Hitung \\
\hline 1 & $\mathrm{X} 1$ & 0,719 \\
\hline 2 & $\mathrm{X} 2$ & 0,633 \\
\hline 3 & $\mathrm{X} 3$ & 0,769 \\
\hline 4 & $\mathrm{X} 4$ & 0,827 \\
\hline 5 & $\mathrm{X}_{5}$ & 0,708 \\
\hline 6 & $\mathrm{X} 6$ & 0,807 \\
\hline 7 & $\mathrm{X} 7$ & 0,705 \\
\hline 8 & $\mathrm{X} 8$ & 0,680 \\
\hline 9 & $\mathrm{Y} 1$ & 0,650 \\
\hline 10 & $\mathrm{Y} 2$ & 0,607 \\
\hline 11 & $\mathrm{Y} 3$ & 0,699 \\
\hline 12 & Y4 & 0,350
\end{tabular}

Berdasarkan hasil uji validitas yang tertera diatas, bahwa setiap butir pertanyaan pada kuisioner memiliki nilai $r$ hitung lebih dari nilai $r$ tabel $(0,279)$ dan dengan nilai signifikansi kurang dari 0,05. Maka model kuisioner yang digunakan peneliti dinyatakan valid.

Reliabilitas dari kuisioner dinilai dari konsistensi responden dalam menjawab pertanyaan dari kuisioner. Kuisioner dinyatakan reliabel apabila nilai cronbach's Alpha lebih dari o,6. Dari hasil uji reliabilitas yang tertera diatas, menunjukan bahwa ketiga variabel memiliki nilai chronbach's alpha lebih dari o,6 yaitu sebesar o,876. Maka indikator variabel dinyatakan reliabel.

\section{Uji Asumsi Klasik}

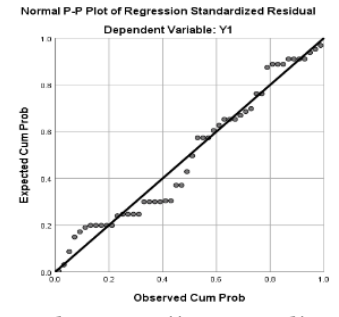

Gambar 2. Uji Normalitas

Sumber: Data diolah

Menurut Ghozali (2016) model dikatakan normal dan lolos uji normalitas apabila titik-titik mengikuti garis diagonal 
pada gambar normal PP-Plot. Berdasarkan hasil uji normalitas pada gambar 2. terlihat bahwa titik-titik menikuti garis diagonal dan berada di sekitarnya. Maka dari itu, model regresi pada penelitian ini dinyatakan berdistribusi normal.

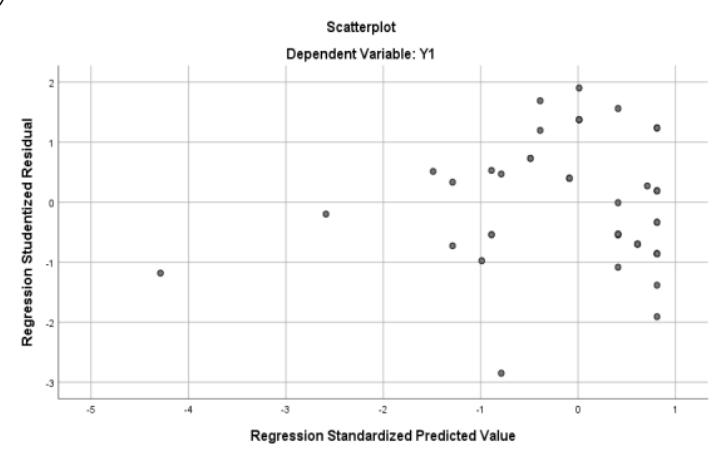

Gambar 3. Uji Heteroskedastisitas Sumber: Data diolah

Berdasarkan grafik scatterplots terlihat bahwa terjadi penyebaran titiktitik pada sumbu Y dan dibawah angka o serta persebarannya secara acak. Maka dari itu model regresi ini dinyatakan layak dan tidak terdapat heteroskedastisitas.

\begin{tabular}{|c|c|c|}
\hline Variabel & Tolarance & VIF \\
\hline $\begin{array}{c}\text { Kualitas } \\
\text { Produk }\end{array}$ & 0,058 & 1,725 \\
\hline Harga & 0,058 & 1,725 \\
\hline
\end{tabular}

Berdasarkan hasil uji yang tertera pada tabel diatas bahwa nilai VIF dari variabel kualitas prodok dan harga adalah sebesar 1,725 yang berarti lebih kecil dari 10. Selain itu, didukung oleh nilai tolerance pada penelitian ini sebesar o, 58 nilainya lebih kecil dari 0,100. Sehingga dari hasil penelitian tersebut disimpulkan bahwa pada model penelitian ini tidak terdapat multikolinearitas.

\section{Uji Hipotesis}

\begin{tabular}{ccc}
\multicolumn{3}{c}{ Tabel 3. Uji t } \\
\hline Variabel & T hitung & Signfikansi \\
\hline $\begin{array}{c}\text { Kualitas } \\
\text { Produk }\end{array}$ & 1.260 & .214 \\
\hline Harga & 3.353 & .002 \\
\hline & Sumber: Data diolah
\end{tabular}

Menurut Ghozali (2016) jika nilai sig. < o,05 maka artinya variabel independent (X) secara parsial berpengaruh terhadap variabel dependent (Y) dan jika dilihat dari t tabel dikatakan signifikan jika t hitung > 0,05/2;50-2-1 = 2,021. Jika dilihat dari tabel diatas bahwa variabel kualitas produk (X1) pada kepuasan konsumen (Y) karena nilai signifikasi nya lebih besar dari 0,05 dan nilai t hitungunya lebih kecil dari 2,021. Tapi harga (X2) berpengaruh signifikan positif secara parsial terhadap variabel kepuasan konsumen (Y) karena nilai t hitung > 2,021 dan nilai sig. <0,05.

\begin{tabular}{c|c|c|}
\multicolumn{3}{c}{ Tabel 4. Uji F } \\
\hline Variabel & T hitung & Signfikansi \\
\hline Kualitas & 15.793 &. .000 $^{\mathrm{b}}$ \\
Produk dan & & \\
Harga & & \\
terhadap & & \\
Kepuasan & & \\
Pelanggan & & \\
\hline
\end{tabular}

Menurut Ghozali (2016) jika nilai Sig. $<$ 0,05 maka artinya variabel independent yaitu kualitas produk dan harga secara simultan berpengaruh terhadap variabel kepuasan konsumen (Y). Karena nilai signifikansi nya lebih kecil yaitu o,ooo. Dan menurut (Sujarweni, 2014) menyatakan bahwa, jika nilai F Hitung > F table. Maka artinya variabel independent (X) secaara simultan berpengaruh terhadap variabel dependet $(Y)$. Nilai $F$ hitung sebesar 15,793 > 3,20 (F tabel dari 2; 50-2). Maka kesimpulan dari tabel diatas menyatakan bahwa kualitas produk (X1) dan harga (X2) secara simultan berpengaruh signifikan positif terhadap variabel kepuasan konsumen (Y).

\section{KESIMPULAN}

Hasil pengujian dengan uji hipotesis secara parsial (uji-t) signifikansi bahwa kualitas produk tidak berpengaruh 
signifikan terhadap kepuasan pelanggan. Variabel harga berpengaruh signifikan terhadap kepuasan pelanggan mahasiswa di Kota Magelang yang menyatakan bahwa terdapat pengaruh terhadap kepuasan pelanggan mereka. Temuan lainnya uji hipotesis secara parsial (uji-F) signifikansi bahwa variabel kualitas dan harga berpengaruh signifikan terhadap kepuasan pelanggan

\section{SARAN}

Perusahaan harus dapat memberikan kualitas dan harga yang sesuai dengan kebutuhan masyarakat. Membuat beragam variasi kualitas dan disesuaikan dengan harganya akan membuat dua masalah pada pelanggan terutama Generasi Z terselesaikan ketika melakukan pembelanjaan online.

\section{DAFTAR PUSTAKA}

Badan Pusat Statistik. (2019). Berita resmi statistik. Bps.Go.Id, 27, 1-52. https://papua.bps.go.id/pressrelease/ 2018/05/07/336/indekspembangunan-manusia-provinsipapua-tahun-2017.html

Amanah, D. (2011). PENGARUH HARGA DAN KUALITAS PRODUK TERHADAP KEPUASAN KONSUMEN PADA MAJESTYK BAKERY \& CAKE SHOP CABANG H.M. YAMIN MEDAN. Jurnal Keuangan \& Bisnis, 3(1), 1-10. https://doi.org/10.36407/jmsab.v3i1. 114

Amstrong, G., \& Kotler, P. (2014). Principles of Marketing (B. Sabran (ed.); 12th ed.). Erlangga.

Dwi, I. K. (2012). Pengaruh Harga dan Kualitas Pelayanan. Jurnal Administrasi Bisnis., Vol.1, No., p3745 .
Ghozali, I. (2016). Aplikasi Analisis Multivariate dengan Program IMB SPSS 23. Badan Penerbit Undip.

Gofur, A. (2019). Pengaruh Kualitas Pelayanan Dan Harga Terhadap Kepuasan Pelanggan. Jurnal Riset Manajemen Dan Bisnis (JRMB) Fakultas Ekonomi UNIAT, 4(1), 3744.

https://doi.org/10.36226/jrmb.v4i1.2 40

Handoko, B. (2017). Pengaruh Promosi, Harga Dan Kualitas Pelayanan Terhadap Kepuasan Konsumen Pada Titipan Kilat JNE Medan. Jurnal Ilmiah Manajemen Dan Bisnis, 18(1), 61-72.

https://doi.org/10.30596/jimb.v18i1. 1098

Haryanto, R. A. (2013). Strategi Promosi, Kualitas Produk, Kualitas Layanan Terhadap Kepuasan Pelanggan Pada Restoran Mcdonaldâ€TMS Manado. Jurnal Riset Ekonomi, Manajemen, Bisnis Dan Akuntansi, 1(4), 14651473.

https://doi.org/10.35794/emba.v1i4.2 923

Kotler. (2012). Prinsip-prinsip Pemasaran. Erlangga.

Lenzun, J. J., Massie, J. D. ., \& Adare, D. (2016). Pengaruh Kualitas Produk, Harga dan Promosi terhadap Kepuasan Pelanggan Kartu Prabayar Telkomsel. Jurnal EMBA, 2(3), 12371245.

https://ejournal.unsrat.ac.id/index.p hp/emba/article/viewFile/5802/5335

Soehardi. (2021). Faktor Pengaruh Kualitas Pelayanan, Harga dan Kepuasan Turis di Tanjung Lesung Provinsi Banten. Jurnal Kajian Ilmiah, 21(2), 147-158. https://doi.org/http://ejurnal.ubhar ajaya.ac.id/index.php/JKI/article/vie $\mathrm{w} / 548$ 
Soehardi, S. (2021). Model Peningkatan Volume Penjualan Melalui Kualitas Produk, Kualitas Pelayanan Dan Loyalitas Kopi Golda. Jurnal Manajemen Strategi Dan Aplikasi Bisnis, 4(2), 353-360. https://doi.org/http://ejournal.impe riuminstitute.org/index.php/JMSAB /article/view/398

Sugiyono. (2017). Metode Penelitian Bisnis (Pendekatan Kuantitatif, Kualitatif, Kombinasi dan R\&D) (3rd ed.). Alfabeta.

Sulistiyana, R. (2015). Pengaruh Fasilitas Wisata Dan Harga Terhadap Kepuasan Konsumen (Studi Pada Museum Satwa). Jurnal Administrasi Bisnis S1 Universitas Brawijaya, 25(2), 86214.

Tempo. (2019). Survei LIPI Ungkap 2 Alasan Warga RI Belanja Online
Produk

Impor. https://bisnis.tempo.co/read/128337 o/survei-lipi-ungkap-2-alasan-wargari-belanja-online-produk-impor

Yulia, P. (2015). Pengaruh Kualitas Produk Dan Harga Terhadap Kepuasan Konsumen Produk M2 Fashion Online Di Singaraja Tahun 2015. Jurnal Jurusan Pendidikan Ekonomi (JJP), $5(1), 1-12$.

Zebua, Y. (2020). Pengaruh Budaya Kerja Dan Promosi Jabatan Dalam Meningkatkan Kinerja Karyawan Pada Pt. Perkebunan Nusantara Iii Labuhan Haji Labuhanbatu Utara. Ecobisma (Jurnal Ekonomi, Bisnis Dan Manajemen), $\quad 7(2), \quad$ 109-124. https://doi.org/10.36987/ecobi.v7i2.1 758 